naturally occurring coloured oxygen carriers such as pyocyanine and lactoflavine increase the oxygen consumption and decrease the lactic acid formation of tissues. Dr. F. Dickens has found that other dyes which are photo-sensitisers, such as phenosafranine, cause increased aerobic lactic acid production. It is remarkable that some irritants such as mustard gas (dichloro diethyl sulphide) and cantharidine prevent or delay the carcinogenic action of tar or similar agents. Dr. I. Berenblum and Dr. L. P. Kendal found that these anti-carcinogenic agents are able to inhibit glycolysis to a greater extent than respiration. It seems to the present writer that this effect may be allied to the effect of iodoacetic acid inhibiting the lactic acid production of muscle.

In the recently formed Cancer Department of St. Bartholomew's Hospital, a million volt X-ray plant is being installed. This should give a more powerful source of short-wave radiation than any radium bomb or X-ray plant at present in use. The results from this plant will be of extreme interest. The present report gives data referring to the radiological treatment of patients in many hospitals, and the pooling of results in this way must be of value in assessing the value of radiological methods in clinical work.

Radiations from radium and X-ray tubes have been used in many experiments on chick embryo and on tadpole tissues. Gamma-rays are found to have most effect on cells that are about to divide ; once cell division has commenced, the process completes itself in a normal manner even in the presence of gamma-rays. The first effect of gamma-radiation is therefore apparently to reduce mitotic activity; but this is followed in turn by periods of apparent recovery, degeneration, abnormal mitosis and final recovery. Further examination of the effect of radium on tissue cultures of chick embryo tissue seems to indicate that the lethal effect depends on the actual amount of radiation rather than the time over which the radiation is spread.

Several specimens of human carcinoma removed in operation have been grown in vitro. An interesting phenomenon demonstrated by Dr. T. Lumsden with tissue culture methods is the action of antibodies capable of killing cancer cells in vitro. The effect of the anti-cancer sera has now been photographed with a cinema camera, and the death of tissue culture cells in the presence of the serum is strikingly shown in the film. It would be of interest to see the effect of the rat anti-cancer serum on tissue cultures of human carcinomata.

It was shown some time ago that snake venom had a toxic effect on malignant growths. The toxic effect of cobra venom on tumours is not prevented by anti-venom serum, and it may be possible to check the toxic effect of the venom on the host without inhibiting the effect on the cancerous growth. This is possibly a hopeful method of attacking the problem of curing cancer. With the active research that is being prosecuted along so many divergent lines in many laboratories, it is possible to say that advances are being continually made, but by which way the goal will be attained it is quite impossible to forecast.

\title{
Obituary
}

\section{Prof. Charles Richet}

A STONE'S throw from the tip of the headland of Giens, in the south of France, there is a cluster of rocky islets. One of the most picturesque of them is pointed at with awe by the local country folk, as the home of a famous old man who carried out mysterious experiments and tried to communicate with the world beyond. It was, indeed, the country home of Prof. Charles Richet, well known in physiology and abnormal psychology, who died on Decem. ber 3 in Paris.

Physiology and medicine owe to Richet the discovery of anaphylaxis, in 1902, which marked a decisive advance in modern medicine, and for which he was awarded the Nobel Prize for Medicine in 1913. This discovery was the result of a series of experiments and researches dating so far back as 1887, a year before the foundation of the Pasteur
Institute, when Richet was the first to carry out an injection of serum into a human being. He was thus one of the founders of serotherapy.

In 1902, Richet was studying with Portier the action of the poison of sea-anemones, when they remarked that dogs which had withstood without any inconvenience an intravenous injection of a minimal dose of an aqueous extract of the tentacles of Actinia, always died after a second but weaker injection administered to them in the same way a few days later. But as this second injection was not strong enough to kill a fresh animal, they came to the conclusion that the first dose of a serum does not always immunise, but on the contrary, renders the organism more sensitive for a certain period and though the effect of the first dose seems to have disappeared. Thus were cleared up many mysterious cases of intoxication and an explanation was forth- 
coming, in particular, of the occurrence of sudden death after repeated and successful administration of serum. The name of 'anaphylaxis' was given by Richet to this type of sensitiveness; and since that time a number of experiments have considerably improved the practice and effectiveness of serotherapy. Richet's "Dictionnaire de physiologie", begun in 1895, is a comprehensive study of the whole subject. $\mathrm{He}$ also wrote "Recherches sur la sensibilité" and "La Physiologie des muscles et des nerfs".

In later years, Richet was interested more and more in psychology and especially in the investigation of borderland phenomena. $\mathrm{He}$ objected to the use of the words "abnormal" or "occult" in connexion with such phenomena, as he held them to be just as natural as any others, and therefore just as much entitled to investigation by the ordinary methods of science. In 1905 , the year in which he was elected president of the Society for Psychical Research, he proposed to give the name Métapsychique to the new science of these phenomena, which he classified under three principal types: cryptesthesy (clairvoyance), telekinesy (action at a distance without eontact) and ectoplasmy (materialisation). $\mathrm{H} \Theta$ contended that as these phenomena occur, they must be real and subject to laws which ought to be discovered by unbiased scientific investigation. These views, which follow closely the work of Sir William Crookes (1872), are illustrated in his "Thirty years of Psychical Research", of which an English translation appeared in 1923, and which is an immense collection of cases of varying evidential value. A smaller volume, partly based on the first, appeared in English in 1929 under the title "Our Sixth Sense". Though Richet considered metapsychics to be still in its infancy, he hoped, with many other distinguished philosophers and psychologists, to see it gradually develop into a full science.

In the realm of psychology proper, Richet adopted the mechanistic theories of Descartes, which he endeavoured to extend to man himself, as had already been suggested by Lamettrie's "L'Homme Machine". Mind cannot be independent of matter, but rather subject to its fundamental laws. There is no gap between the psychical and the physiological ; and the 'higher' faculties of man can be easily explained by inferior phenomena with such laws as those of reflex movements, of irritation and of association ("Traité de psychologie générale", 1912). Consequently, if introspection is useful for the study of the decisions of the conscience, it cannot help in the investigation of psychological phenomena, which must be entirely experimental. This ruthless de. terminism, which was well in keeping with the prevalent ideas among French men of science at the beginning of this century, caused Richet to deny the necessity of any metaphysical conceptions and to predict the death of metaphysics.

Charles Richet was born in Paris on August 25, 1850. Following the footsteps of his father and his maternal grandfather, he studied science and medicine and obtained an M.D. at the Paris Faculty of Medicine in 1876. He then worked under Marey at the Collège de France, and in 1887 he was appointed professor of physiology and medicine in the University of Paris. His first discovery was that of the presence of hydrochloric acid in the gastric juice. $\mathrm{He}$ investigated the relation between respiration and the area of body surface; and he carried out a good deal of research on animal heat. He also studied the problem of epilepsy and the treatment of tuberculous patients by dieting them on raw meat.

The interests of Charles Richet were not limited to physiology and psychology. He followed from the beginning the development of aeronautics and he made a name for himself as a novelist and a playwright, two of his plays ("Socrate" and "Circé") having been performed at the Odéon, in Paris. He was also a convinced pacifist and president of the Société pour l'Arbitrage entre les Nations. A member of the Academy of Medicine since 1896, Charles Richet was elected in 1914 to the Academy of Sciences. His scientific jubilee was celebrated in 1926, at the Paris Academy of Medicine, with the official participation of savants from many countries. On that oceasion, Marshal Foch invested him with the insignia of Grand Cross of the Legion of Honour.

T. G.

WE regret to announce the death last September in his seventieth year of the eminent Italian physiologist, Prof. Luigi Mariano Patrizi, who was born at Recanati near Ancona on September 13, $1866 . \mathrm{He}$ studied under J. Moleschott in Rome, where he qualified in 1890. After serving as assistant to Angelo Mosso at Turin, he occupied in succession the chair of physiology at Ferrara (1894), Sassari (1896) and Bologna (1924). During the period 1911-24 he was professor of criminal anthropology at Turin. His work was chiefly concerned with the psychometry of attention, the physiology of the intellect and criminal physiology and psychiatry. His publications include a psycho-anthropological study of Leopardi and his family (1896), the physiology of the bandit Giuseppe Musolino (1904), "The Orator" (1912), "After Lombroso" (1916) and a work on the physio. logical measurement of the emotions and passion (1924).

We regret to announce the death on November 19, at the age of sixty-six years, of Dr. Dan McKenzie, who besides being a consulting surgeon in diseases of the ear, nose and throat and a former editor of the Journal of Laryngology and Otology, was a keen student of medical history and folk-lore. In addition to a textbook on his speciality, of which the second edition appeared in 1927, he was the author of "The City of Din" (1916), "Aromatics and the Soul : a Study of Smells" (1923), and "The Infancy of Medicine: an Enquiry into the Influence of FolkLore upon the Evolution of Seientific Medicine" (1927), of which a notice appeared in NATURE of January 28, 1928 , p. 133. 